\title{
Significant factors for enabling knowledge sharing between government agencies within South Africa
}

\begin{tabular}{|c|c|}
\hline $\begin{array}{l}\text { Authors: } \\
\text { Avain Mannie } \\
\text { Herman J. var } \\
\text { Chris M. Ader }\end{array}$ & Niekerk $^{1,2}$ \\
\hline $\begin{array}{l}\text { Affiliations: } \\
{ }^{1} \text { Department } \\
\text { Economics Sc } \\
\text { Mandela Met } \\
\text { University, Po } \\
\text { South Africa }\end{array}$ & $\begin{array}{l}\text { f Business and } \\
\text { ence, Nelson } \\
\text { opolitan } \\
\text { t Elizabeth, }\end{array}$ \\
\hline $\begin{array}{l}{ }^{2} \text { Suritec, Cape } \\
\text { South Africa }\end{array}$ & Town, \\
\hline $\begin{array}{l}\text { Corresponde } \\
\text { Avain Mannie }\end{array}$ & ce to: \\
\hline $\begin{array}{l}\text { Email: } \\
\text { avain.mannie }\end{array}$ & @gmail.com \\
\hline $\begin{array}{l}\text { Postal addres } \\
\text { 1A Shirley Str } \\
\text { Park, Port Eliz } \\
\text { South Africa }\end{array}$ & $\begin{array}{l}\text { abeth } 6045 \text {, } \\
\text { abewton }\end{array}$ \\
\hline $\begin{array}{l}\text { Dates: } \\
\text { Received: } 27 \\
\text { Accepted: } 19 \\
\text { Published: } 18\end{array}$ & $\begin{array}{l}\text { Mar. } 2013 \\
\text { Aug. } 2013 \\
\text { Oct. } 2013\end{array}$ \\
\hline $\begin{array}{l}\text { How to cite tl } \\
\text { Mannie, A., V } \\
\text { H.J. \& Adendo } \\
2013 \text {, 'Signific } \\
\text { for enabling k } \\
\text { sharing betwe } \\
\text { agencies with } \\
\text { SA Journal of } \\
\text { Management } \\
\text { \#569, 8 pages } \\
\text { org/10.4102/ }\end{array}$ & $\begin{array}{l}\text { is article: } \\
\text { n Niekerk, } \\
\text { rff, C.M., } \\
\text { ant factors } \\
\text { nowledge } \\
\text { en government } \\
\text { n South Africa', } \\
\text { nformation } \\
\text { 15(2), Art. } \\
\text { http://dx.doi. } \\
\text { ajim.v15i2.569 }\end{array}$ \\
\hline $\begin{array}{l}\text { Copyright: } \\
\text { (C) 2013. The } \\
\text { Licensee: AOS } \\
\text { OpenJournals } \\
\text { is licensed un } \\
\text { Creative Com } \\
\text { Attribution Lic }\end{array}$ & $\begin{array}{l}\text { IS } \\
\text { Ihis work } \\
\text { Ther the } \\
\text { nons } \\
\text { ense. }\end{array}$ \\
\hline Read online: & \\
\hline 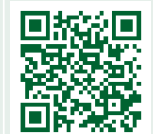 & $\begin{array}{l}\text { Scan this QR } \\
\text { code with your } \\
\text { smart phone or } \\
\text { mobile device } \\
\text { to read online. }\end{array}$ \\
\hline
\end{tabular}

Background: Globally, organisations have recognised the strategic importance of knowledge management $(\mathrm{KM})$ and are increasingly focusing efforts on practices to foster the creation, sharing and integration of knowledge.

Objectives: This study aimed to validate the significant factors that influence the effectiveness of KM between government agencies in South Africa. The commonly identified pillars of KM in the extant literature served as a primary framework in establishing these factors.

Method: Data were gathered using an electronic survey made available to different national government agencies within the security cluster. Responses were analysed using structural equation modelling.

Main findings: Existing literature highlighted organisational culture, learning organisation, collaboration, subject matter experts and trust as being determinants for knowledge management. The first two were identified as the most significant factors for knowledge sharing to succeed.

Conclusion: Whilst there is universal consent as to the strategic importance of KM, actionable implementation of knowledge sharing initiatives appears to be lacking. This study emphasised the fact that leaders must instil a knowledge sharing culture either through employee performance contracts or methods such as the balanced score card. The study also showed that it is imperative for leaders to acknowledge that KM is a multi-faceted discipline that offers strategic advantages. Leaders of developing countries should note that they are on a developmental journey. This requires their organisations to be learning organisations, which necessitates a change in the organisational culture and knowledge interventions through their academies of learning.

\section{Introduction}

It is interesting to note that infamous United States of America gangster Al Capone (during the Prohibition period) was charged for tax evasion rather than the assumed illegal sale of alcohol. This point highlights the fact that a collective knowledge sharing effort between government agencies is key in finding alternate solutions for problem solving.

After further elaboration on the problem in this section, the commonly identified factors for knowledge sharing as per the global literature will be looked at. These factors are depicted in the theoretical model (see Figure 1), which is highlighted below. Thereafter, a brief discussion on the significant factors (independent variables) and dependant variable are elaborated upon. The research design and approach is then discussed, whilst the results and conclusion are finally conveyed.

The strategic importance of knowledge management (KM) has been widely acknowledged (Alavi and Leidner 1999; Bebensee, Helms \& Spruit 2011; Cortes, Sa'ez \& Ortega 2007; Ibrahim \& Reed 2009). Whilst it is evident that knowledge management in the private sector has made tremendous inroads, the application of KM practices in the public sector has followed only in a limited fashion. The potential for KM in assisting the public sector is however widely encouraged and recognised (Cong \& Pandya 2003; Durrant 2001; Salavati, Shafei \& Shaghayegh 2010; Yuen 2007).

From a South African perspective, it is accepted that the country is an emerging democracy when compared to the global village. As a developing country, it has many challenges, including poverty eradication, skills shortages and high levels of crime. It has been found that, more often than not, knowledge is not effectively shared because organisations and business units tend to operate in silos (Rogers 2007). Ultimately, mandates of government organisations or business units are seldom achieved, resulting in non-service delivery to the citizens of the country. Organisations 
pursuing knowledge management in general, and knowledge sharing in particular, have traditionally focused on the information technology infrastructure (Davenport, Delong \& Beers 1998). Whilst information technology is important to the overall knowledge management endeavour, a lack of attention to cultural factors has proven to be a roadblock to any sustainable success. The researchers have witnessed several deployments of information management and team collaboration solutions that have failed to meet their objective of facilitating consistent information and knowledge exchange. Whilst there may be many factors contributing to these deployment failures (for example insufficient training, application champions, communication or support), the organisations in question neglected to take into account the social and motivational drivers behind why an employee would share what they know regardless of what tool was available.

In this study the literature findings indicated that in attempting to resolve problems, and if used effectively, the discipline of knowledge management can be a critical tool in assisting government agencies to inculcate a knowledge sharing culture and, ultimately, achieve their mandates.

\section{Problem statement and explanation}

Indications are that knowledge sharing amongst South African government agencies is limited. In his address at the Knowledge Management conference at Stellenbosch Business School, former president Thabo Mbeki pointed out that the purpose of the conference was to discuss: 'the role of knowledge in the betterment of society' (see Mbeki 2012:4). This may be linked to the 'Batho Pele' principles, which aim to achieve overall service delivery. The problem may be stated succinctly as follows: There is insufficient and ineffective knowledge sharing between government agencies in South Africa in the pursuit of effective problem solving.

In 2007, Rogers interviewed renowned ichthyologist and environmental activist Professor Peter Britz on the subject of abalone poaching. In this interview, Professor Britz stated categorically that government agencies were not effectively working together towards resolving the problem (Rogers 2007). Britz's comment highlighted the lack of cooperation between and inefficiency of relevant government agencies. It is against this backdrop that the researchers proposed investigating the state of knowledge management in selected government agencies, thereby assisting to establish knowledge sharing practices within and between various government agencies. The opportunity in this instance (thinking back to the Capone case) is that if a culture of sharing is installed in the seemingly siloed mentality of government, then the KM discipline will be in action and problem solving will be greatly enhanced.

Previous research by McDermott and O'Dell (2005:84) and Yao, Kam and Chan (2007:65) highlighted numerous barriers to knowledge sharing, including aspects such as organisational culture and leadership. Other factors and barriers may also be prevalent, such as a lack of an appropriate information and communication technology (ICT) infrastructure, no knowledge sharing practices such as communities of practice and a lack of trust within organisations and even in government itself (Cloete 2007; Riege 2005; Yuen 2007). The theoretical model below is a reference for the commonly identified enablers for knowledge sharing as well as being a basis for the list of hypotheses.

\section{The theoretical model and the factors influencing the perceived effectiveness of knowledge management}

In this investigative theoretical model (see Figure 1), the dependent variable is the perceived effectiveness of knowledge sharing between South African government agencies. The intervening variables were initially knowledge management and a relatively new concept in military circles known as netcentricity. With regard to the independent variables, it is widely acknowledged by authors such as Bechina and Ndlela (2009) and Hsu (2006) that for knowledge management to succeed, certain 'enablers' - also known as pillars or crucial drivers - need to be present. In order to focus on the pillars of KM, the researchers used the adapted model of Stankosky's KM Pillars to Enterprise Learning (Cranfield \&Taylor 2008). This theoretical model was amended during the research methodology phase and will be appropriately expanded upon. The theoretical model and the hypothesised interrelationships between the variables are outlined in Figure 1.

The objective of the study was primarily to investigate and test the impact of independent variables (identified in the literature) on the perceived effectiveness of knowledge management in government agencies. Furthermore, the study intended to investigate barriers influencing knowledge sharing. As such, a number of hypotheses were formulated to test these barriers:

- Hypothesis 1: There is a positive relationship between effective leadership and the perceived effectiveness of knowledge sharing.

- Hypothesis 2: There is a positive relationship between a collaborative organisational culture and the perceived effectiveness of knowledge sharing.

- Hypothesis 3: There is a positive relationship between ICT application and the perceived effectiveness of knowledge sharing.

- Hypothesis 4: There is a positive relationship between a continuously learning organisation and the perceived effectiveness of knowledge sharing.

- Hypothesis 5: There is a positive relationship between communities of practice and the perceived effectiveness of knowledge sharing.

- Hypothesis 6: There is a positive relationship between policy and legislation support and the perceived effectiveness of knowledge sharing.

- Hypothesis 7: There is a positive relationship between high levels of trust embedded in an organisation and the perceived effectiveness of knowledge sharing. 


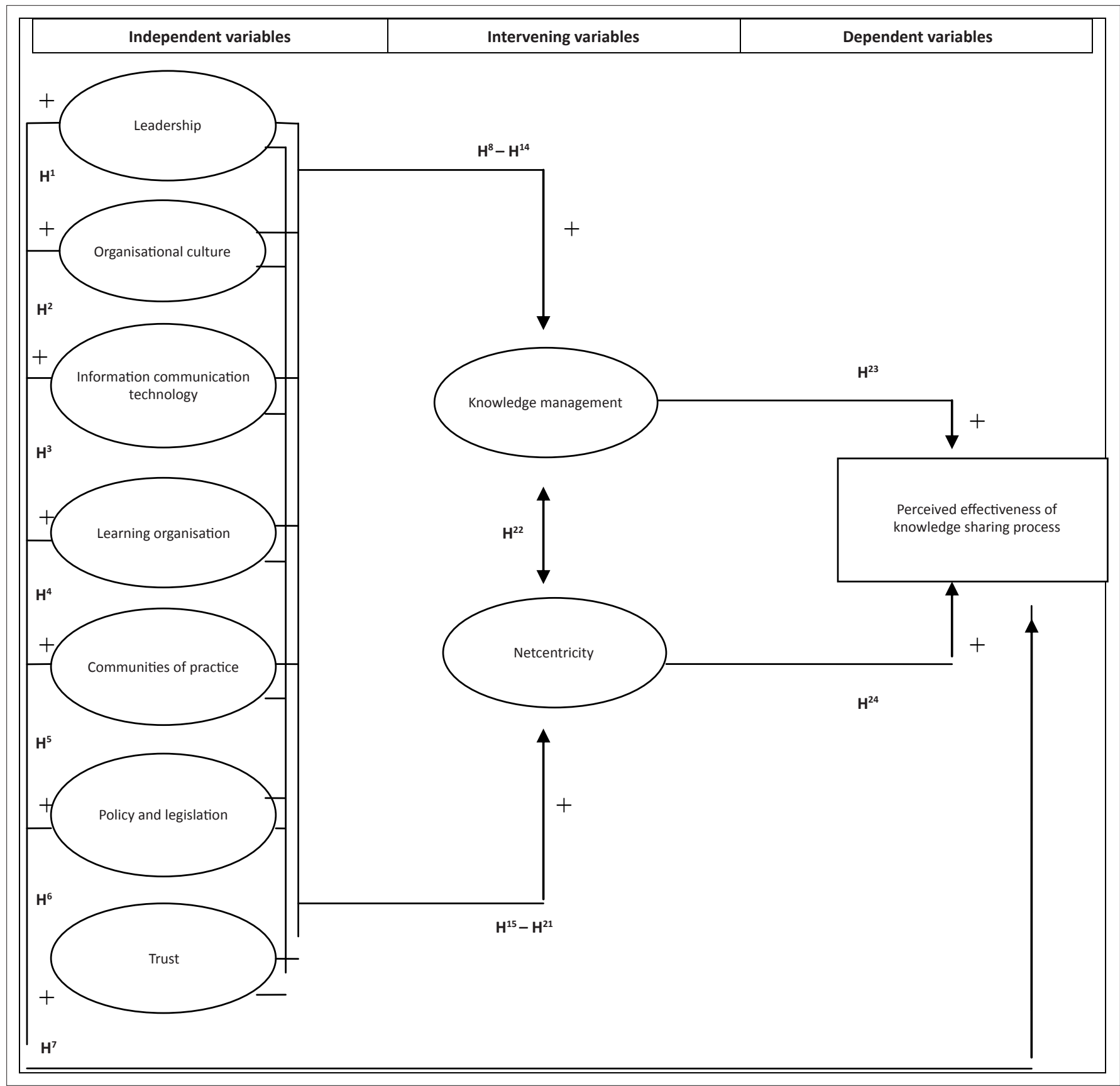

FIGURE 1: Theoretical model of perceived effectiveness on knowledge sharing.

Only the significant factors or independent variables (organisational culture and a learning organisation) identified through this study and the dependent variable (knowledge management) will be discussed next.

\section{Organisational culture}

In this article, organisational culture is defined as the perception of the character of an organisation by its employees. The individual perceptions combine to create the collective organisational culture. If the culture is collaborative, then knowledge sharing amongst employees should be occurring. However, a lack of important enablers such as rewards, or the presence of noticeable barriers, may inhibit a sharing culture (Riege 2005). As asserted by Riege (2005), it is thus critical to identify the barriers in order to remove them so that knowledge sharing may become a common culture with the relevant organisation.

Kreitner, Kinicki and Buelens (1999:58) identified four functions of organisational culture: 'it gives members an organisational identity; it facilitates collective commitment; it promotes social system stability; and it shapes behaviour by assisting members to make sense of their surroundings'. If the leadership commits and drives a collaborative, learning culture, then employees at lower levels will acknowledge that their leaders indeed reward innovative and collaborative work behaviour. Conversely, if no reward systems are put in place, then the motivation to share will be inhibited (Riege 2005). This highlights the fact that variables such as leadership and organisational culture are interdependent. 
Campbell (2009) pointed out that social factors, like trust and collaboration, also form part of the overall organisational culture. Thus, by focusing on developing organisational culture, these factors will improve. Similarly, by acknowledging an organisation as a learning organisation, subject matter experts are more likely to be recognised, empowered and used in order to share their knowledge with employees and thus the overall organisation. The point being driven by the researchers is that although social factors like collaboration and trust were not found to be significant, they are nevertheless important as they form part of the overall culture, which is found to be significant in this study.

The issue of trust can be widely accepted as being closely linked to organisational culture. Globally, trust in governments has come under scrutiny because of the corrupt practices of leaders. Increasingly, people are losing trust in governments and their leaders (Cloete 2007). With technology evolving at a rapid pace, an increasingly competitive global market and the need for quicker decision-making, organisations require external support in terms of technology and information sources (Foos, Schum \& Rothenberg 2006). These types of interactions, however, usually require an element of trust (Paroutis \& Al Saleh, 2009; Scarso \& Bolisani 2011).

\section{Learning organisation}

For the purposes of this article, a learning organisation is one that promotes the exchange of information between employees and creates a more knowledgeable workforce. An organisation requires a particularly flexible organisational structure, in which people will accept and adapt to new ideas and changes through a shared vision (Schein 1996). This brings a new perspective and growing importance to organisational knowledge, and the learning organisation accepts the challenge of creating a culture of managing knowledge. Clearly, a learning organisation is also driven by its leadership and culture.

Goh (2002:23) viewed 'knowledge transfer' as a key dimension of a learning organisation and hence as a critical factor for knowledge management. One of the methods used for knowledge transfer by learning organisations is that of initiating communities of practice. Communities of practice are therefore viewed as 'actionable' means of creating a sharing culture whilst ensuring a sustainable platform with known knowledge workers and a suitable method for communicating, either in a virtual set-up or within an informal meeting strategy (Cross, Borgatti \& Parker 2001). Kimble and Hildreth (2005:103) concurred, considering communities of practice as groups of people who are joined together 'with an internal motivation and common purpose'. Key to this group of people is the relationship that is built between the members. Ardichvili, Page and Wentling (2003:64), who focused more on virtual communities of practice, indicated that one of the critical success factors of this type of learning and sharing in an organisation is that there must be active participation. Ardichvili et al. (2003) also suggested that the group must have a common motive for actively communicating and sharing. Furthermore, these authors viewed intrinsic motives to be of more influence than extrinsic motives such as monetary reward.

\section{The dependent variable: Knowledge management}

Knowledge management has emerged in the last decade as an important organisational concept and whilst definitions still differ on what KM is, consensus is emerging. In a study by Kippenberger (1998:14) involving nearly 40 respondents, the majority of respondents agreed that knowledge management is defined as 'the collection of processes that govern the creation, dissemination, and utilisation of knowledge to fulfil organisational objectives'. In terms of the global, strategic importance of knowledge management, a report from the Economic Intelligence Unit (2006:3), which assessed likely changes to the global economy between 2006 and 2020, stated that knowledge management as a discipline would be the major boardroom challenge. In fact, the report highlighted survey results in which knowledge management was rated the area that offered the greatest potential for productivity gains. Yuen (2007), in a global workshop held on managing knowledge to build trust in governments, highlighted the explosion of digital connectivity and further stated that most governments had accepted the use of information technology (IT) for knowledge and ultimate public sector reform. The strategic importance of the knowledge management discipline for governments and organisations has also been acknowledged by a number of subject matter experts, including Bebensee et al. (2011), Cheng, Ho and Lau (2009), Cortes et al. (2007), Ibrahim and Reid (2009), Jakubik (2007), Riege (2005) and Tiago, Tiago and Couto (2009).

Knowledge management, in its simplest sense, establishes the ways in which organisations create, retain and share knowledge. As knowledge management is a broad discipline (Dalkir 2005), the thinking is that if organisations embrace the discipline, then knowledge sharing methodologies and processes will have a platform to ensure the success of knowledge sharing.

The scope of this article is the public sector and, as acknowledged by various authors, knowledge management in government is relatively new (Cloete 2007; Cong \& Pandya 2003; Gaffoor \& Cloete 2010; Riege 2005). By implication, the successes of knowledge management in the private sector need to be practised in the public sector as well. This article therefore seeks to identify the level of understanding of knowledge management as well as the key factors that contribute to effective management of knowledge in those government agencies whose mandate and powers are to enforce laws for the betterment of society and the country as a whole.

The following section will expand on the research design and research objectives.

\section{Research design Research approach}

Whilst government has many departments overlooking many sectors, this article focused on a particular sector: 
the criminal sector. Departments tasked with resolving the problem of abalone poaching were selected, primarily due to the recent publicity in local newspapers, such as the Eastern Cape Herald (see Rogers 2007), which highlighted the problem of government agencies not operating collaboratively. The regional managers of the relevant agencies operating in the Eastern Cape were initially identified due to the researchers being based in the Eastern Cape. However, to ensure national benefit is obtained, the researchers further targeted the national counterparts via the regional managers, in order to adhere to government agency protocols.

Through the initial engagement, it became apparent that the relevant agencies required total anonymity due to the nature of criminal investigations. As such, it must be emphasised that the relevant government agencies shall not be named, especially with regard to the analysis and findings. Instead, specific government agencies will be referred to as Agency A, Agency B and so on, in order to respect the anonymity requested. For purposes of this study, a quantitative and positivist approach appeared to be the most appropriate. The rationale for selecting the positivist approach was primarily based on the following facts:

- The researchers were independent.

- A relatively large sample was used.

- Hypotheses were formulated in order to be tested.

\section{Research method}

For this research, a comprehensive questionnaire, covering the identified independent variables required for knowledge management, was made available electronically and in hard copy where required. In terms of the research participants, relevant employees, mainly within the audit and investigations units within the relevant government agencies, were identified as appropriate for this research. After obtaining approval from the selected agencies to conduct the research, probability sampling was used: all employees (mainly team members) were invited to participate in the research.

\section{Research procedure}

After obtaining permission to conduct the research, the questionnaire was made available to participants between April and July 2012 on the Nelson Mandela Metro University (NMMU) website. Participants were informed via a research engagement letter and the necessary Internet link was also communicated. The research objectives, instructions on how to complete the questionnaire and the fact that responses were to be held in strictest confidence were further highlighted in the formal communications.

In terms of the statistical analysis, the statistical technique of structural equation modelling was used in this study to assess hypothesised relationships in the theoretical model, in order to understand the state of knowledge sharing in and between government agencies in South Africa.

\section{Results \\ Validation process}

In order to assess the discriminant validity of the measuring instrument, exploratory factor analysis (EFA) using a maximum likelihood EFA was applied, such that latent constructs contained in the original variables could be identified. In order to determine how many factors to extract, a combination of several criteria, namely the Eigenvalues, the percentage of variance criterion, and the scree test criterion, was used (Hair et al. 1998:104). During this step, it was found that there was a lot of definitional overlap between constructs, which led the researchers to conclude that some of the variables measured the 'same thing'. Due to a lack of discriminant validity, the theoretical model had to be adapted. Emanating from this exploratory factor analysis, the model was split and grouped into three categories of outcome variables: organisation variables, intervening variables and interpersonal variables.

In order to assess the adequacy or the suitability of the respondent data for factor analysis, the software programme SPSS, which includes Bartlett's test of sphericity and the Kaiser-Meyer-Olkin (KMO) measure of sampling adequacy, was applied. According to Kaiser (1974), a KMO of 0.70 is considered 'middling', whereas values below 0.70 are considered 'mediocre', 'miserable' or 'unacceptable'. Consequently, for the purpose of this study, data with KMOs of more than $0.70(p<0.05)$ were considered factoranalysable. Eigenvalues are used to explain the variance captured by the factor. During a factor analysis, a number of values are generated. These values are the correlations between each variable and each factor, and are known as factor loadings. According to Hair et al. (2006:128), factor loadings of 0.30 and 0.40 are considered significant for sample sizes of 350 and 200 respectively. In this study, items that displayed no cross-loadings, that loaded to a significant extent on one factor only, and had factor loadings of 0.35 or higher were considered significant and regarded as evidence of discriminant validity.

In the EFA, the initial numbers of factors to be extracted were not specified. However, the Eigenvalues determined the number of factors to be used (highlighted in Table 1, Table 2 and Table 3). A process of deleting items that did not demonstrate sufficient discriminated validity ensued; the exploratory factor analysis was re-run until all the remaining items loaded to a significant extent $(p>0.35)$ with no cross-loadings (i.e. loaded on only one factor). The most interpretable factor structures are presented in the tables. All items with loadings of over 0.35 were deleted.

Although an Eigen value of greater than 1 is generally accepted, the value of 0.941 for factor 4 was deemed as acceptable in this instance as it was interpretable.

Table 1 indicates that a total of 18 organisational items were loaded on four factors, and explain a total of $62.1 \%$ of the variance in the data. 
Table 2 indicates that a total of 15 items measuring the intervening variables were grouped into three factors, and explain a total of $57.6 \%$ of the variance in the data. Out of the three factors identified, the factor information sharing was removed due to poor construct validity.

Table 3 indicates that a total of 11 items measuring the interpersonal variables loaded on three factors, namely internal communities of practice, trust and external communities of practice, and explain a total of $63.3 \%$ of the variance in the data. Whilst two of the initial six items loaded onto trust, two of the remaining four (TRUST2 and TRUST6) loaded onto the communities of practice factors. With regard to both internal and external communities of practice factors, all of the seven items loaded, with the exception of COP1.

The variables (internal communities of practice and external communities of practice) combined such that they merged with the variable learning organisation. The initially identified independent variable of trust was deemed as the appropriate variable when all three factors merged.

The interpretation of the EFA indicates that the items and constructs (factors) remaining in the data demonstrate sufficient evidence of discriminated validity. The reliability of the research instrument will be discussed next.

\section{Reliability of the research instrument}

For this study, the software application IBM SPSS Version 19.0 for Windows ${ }^{\circledR}$ was used to measure the Cronbach alpha for each of the identified factors. A Cronbach alpha of greater than 0.70 was required in order to regard a score as reliable. A summary of the variables in terms of reliability is presented in Table 4.

As listed in Table 4, all variables were reliable (having Cronbach alpha values greater than 0.70 ). From the originally proposed independent variables of the proposed theoretical model, one (policy and legislation) was removed as it did not demonstrate sufficient discriminate validity during the initial data analysis process. A further five variables were removed from the model as the exploratory factor analysis conducted was unable to confirm adequate discriminant validity amongst all the latent variables. Noticeably, some items from the deleted variables did, however, load on other factors in the exploratory factor analysis. For instance, one item expected to measure the variable leadership (L6) loaded with items ICO3, CULT7 and LO7 to form a newly identified latent variable termed subject matter expert. The item (NETC10) loaded with other items NETC9, SUCC6, KNOW5 and KNOW6 to form a variable termed collaboration. In essence, although the above terms were removed via the exploratory factor analysis, they were instrumental in forming new variables.

The latent variable of knowledge sharing, which was first proposed as the dependent variable, loaded together with the initial intervening variable (knowledge management).
TABLE 1: Rotated factor loadings: Organisational variables.

\begin{tabular}{|c|c|c|c|c|}
\hline Item & $\begin{array}{l}\text { Factor 1: } \\
\text { Learning } \\
\text { Organisation } \\
\text { (LO) }\end{array}$ & $\begin{array}{l}\text { Factor 2: } \\
\text { Netcentricity } \\
\text { (NETC) }\end{array}$ & $\begin{array}{l}\text { Factor 3: } \\
\text { Subject matter } \\
\text { expert } \\
\text { (EXPERT) } \\
\end{array}$ & $\begin{array}{l}\text { Factor 4: } \\
\text { Organisation } \\
\text { culture } \\
\text { (CULT) }\end{array}$ \\
\hline LO4 & .792 & .064 & -.032 & .048 \\
\hline COP4 & .745 & .079 & .035 & .058 \\
\hline CULT5 & .687 & -.026 & .041 & -.059 \\
\hline ICO5 & .566 & -.196 & .130 & -.144 \\
\hline LO3 & .501 & -.069 & .059 & -.221 \\
\hline LEAD4 & .451 & -.030 & .028 & -.298 \\
\hline ICO3 & .030 & .730 & .137 & .054 \\
\hline LO2 & -.037 & .398 & -.104 & -.208 \\
\hline LO7 & -.032 & .009 & .920 & -.048 \\
\hline LEAD6 & .264 & .188 & .415 & .012 \\
\hline CULT7 & .139 & -.026 & .360 & -.278 \\
\hline CULT2 & .030 & .036 & .052 & - \\
\hline CULT3 & -.035 & .164 & .077 & - \\
\hline CULT4 & -.003 & -.073 & .304 & - \\
\hline LEAD2 & .309 & .101 & -.020 & - \\
\hline LEAD1 & .277 & .058 & -.011 & - \\
\hline CULT1 & .194 & .077 & -.049 & - \\
\hline CULT6 & .272 & .100 & .183 & - \\
\hline Eigen value & 8.319 & 1.454 & 1.069 & 0.941 \\
\hline
\end{tabular}

LO, learning organisation; NETC, netcentricity; EXPERT, subject matter expert; CULT, organisational culture; COP, communities of practice; ICO, internal communities of practice; LEAD, leadership.

TABLE 2: Rotated factor loadings: Intervening variables.

\begin{tabular}{llll}
\hline Item & $\begin{array}{l}\text { Factor 1: } \\
\text { Knowledge } \\
\text { management } \\
\text { (KNOW) }\end{array}$ & $\begin{array}{l}\text { Factor 2: } \\
\text { Collaboration }\end{array}$ & $\begin{array}{l}\text { Factor 3: } \\
\text { Information } \\
\text { sharing }\end{array}$ \\
\hline SUCC1 & .839 & -.052 & -.052 \\
KNOW1 & .797 & -.022 & -.040 \\
SUCC2 & .786 & .052 & -.080 \\
KNOW2 & .695 & -.097 & -.026 \\
SUCC5 & .674 & .028 & -.003 \\
KNOW3 & .653 & .039 & .070 \\
KNOW4 & .599 & .061 & .208 \\
SUCC3 & .504 & .125 & .145 \\
NETC10 & .007 & .762 & -.026 \\
KNOW5 & -.084 & .752 & .118 \\
SUCC6 & -.080 & .692 & -.048 \\
KNOW6 & .188 & .548 & -.089 \\
\hline NETC9 & .020 & .441 & .066 \\
SUCC4 & .209 & -.021 & .723 \\
\hline NETC8 & -.042 & .015 & .364 \\
\hline Eigen value & 5.081 & $\mathbf{2 . 3 9 4}$ & $\mathbf{1 . 1 7 5}$ \\
\hline KNOW, & & &
\end{tabular}

KNOW, knowledge management; SUCC, success of knowledge sharing; NETC, netcentricity.

TABLE 3: Rotated factor loadings: Interpersonal variables.

\begin{tabular}{llll}
\hline Item & $\begin{array}{l}\text { Factor 1: } \\
\text { Communities } \\
\text { of practice } \\
\text { (Internal) (COP) }\end{array}$ & Factor 2: Trust & $\begin{array}{l}\text { Factor 3: } \\
\text { Communities } \\
\text { of practice } \\
\text { (External) (COP) }\end{array}$ \\
\hline COP3 & .876 & .043 & .122 \\
COP5 & .703 & -.043 & -.068 \\
COP4 & .491 & .135 & -.169 \\
TRUST6 & .490 & .032 & -.150 \\
TRUST4 & .021 & .831 & .059 \\
TRUST5 & .049 & .385 & -.265 \\
TRUST3 & -.001 & -.045 & -.725 \\
COP2 & -.075 & .111 & -.656 \\
COP6 & .111 & -.003 & -.622 \\
TRUST2 & .218 & .001 & -.545 \\
COP7 & .345 & .068 & -.411 \\
\hline Eigen value & 5.061 & 0.990 & $\mathbf{0 . 9 1 4}$ \\
\hline
\end{tabular}

COP, communities of practice; TRUST, trust. 
The analysis then combined the two variables (knowledge sharing and knowledge management), which subsequently reflected knowledge management as the dominant dependent variable. As such, both intervening variables (knowledge sharing and netcentricity) were removed due to poor discriminant validity. As a result of the factor analysis, the original theoretical model and the associated hypotheses formulated were revised.

Through this research, five primary determinants of perceived effectiveness of knowledge management for South African government agencies were examined.

The research has confirmed that the factors organisational culture and learning organisation have a significant impact on the effectiveness of knowledge management. The literature revealed that there are numerous factors impacting on organisational culture, hence the need to identify what these factors are and their levels of importance. In the study conducted, latent social factors like collaboration and trust were identified as factors that need to be looked at if a positive collaborative and trusting culture is the objective. It must be noted that understanding a culture and identifying the complex knowledge sharing processes is not an easy task. As such, more research needs to be done, especially within the public sector and in terms of understanding what employees want', what drives employees to hoard or share knowledge and what knowledge sharing methodology is best suited for the specific public organisations. One thing is certain: a collaborative effort involving all stakeholders is required in order to ensure the effective implementation of knowledge management in the public sector in South Africa. In support of the critical factors found pertinent in this study, the following model for knowledge management in the public sector is proposed.

Based on the current literature on $\mathrm{KM}$ and the significant factors identified in this study, the use of the knowledge tree model was seen as an ideal comparison between a tree and a typical organisation. A tree, similar to a learning organisation should grow continuously. Furthermore, trees, like organisations and governments, have various branches which requires nurturing - similar to learning in the organisational sense. The culture of an organisation, which cannot be simply interpreted or viewed at first glance, is like the underlying roots of a tree. The model above has at its centre (central strategy of an organisation) the core knowledge management discipline; the various branches of government have to collaboratively support and influence the direction of knowledge in order to grow and improve on service delivery and ultimate problem solving. Leadership and policymaking are important in understanding and investigating the 'factors beneath the surface' of the tree (organisation), in that they need to look 'beyond and beneath' in order to deal with organisational culture and learning issues, as issues of trust and subject matter experts are to be viewed as the roots 'below the surface'. A relatively young developing country like South Africa is to be viewed as a growing tree
TABLE 4: Summary of all variables in terms of reliability.

\begin{tabular}{lll}
\hline Variable & Eigen value & Cronbach alpha \\
\hline Organisational culture & 0.941 & 0.866 \\
Learning organisation & 8.319 & 0.860 \\
Subject matter expert & 1.069 & 0.708 \\
Collaboration & 2.394 & 0.771 \\
Trust & 0.990 & 0.771 \\
Knowledge management & 5.081 & 0.887 \\
\hline
\end{tabular}

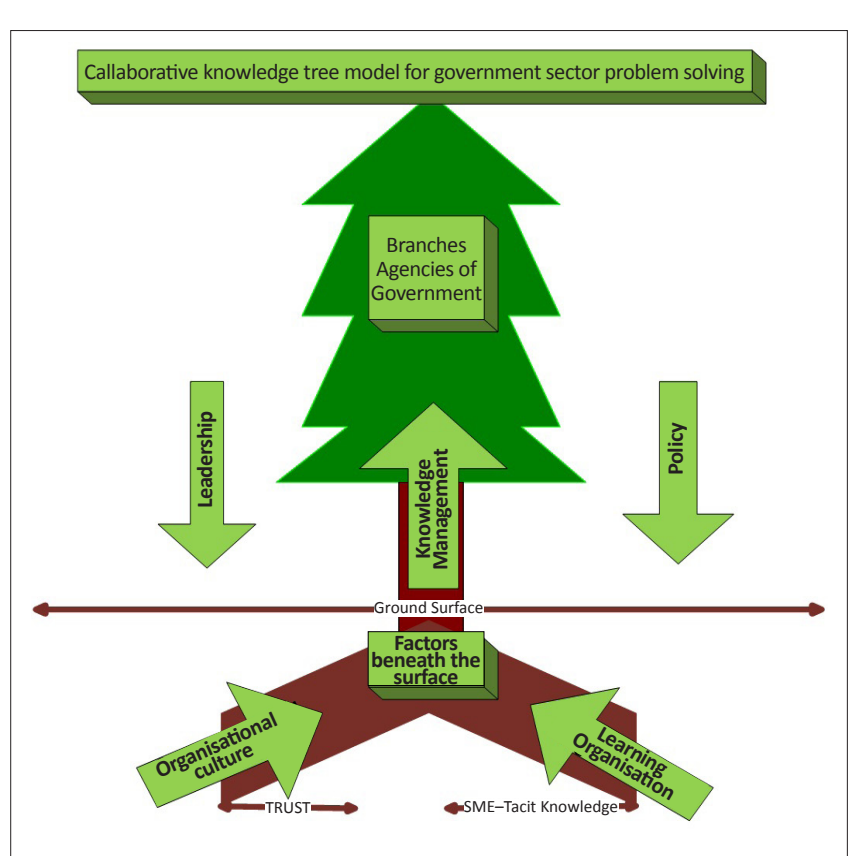

FIGURE 2: Collaborative knowledge tree model for public sector problem solving.

in this instance, which requires the caretakers (leaders) to ensure that the 'seeds and fertiliser' (organisational culture and learning) are firmly planted in order for the country to continuously grow and provide the fruits of success.

\section{Conclusion}

The study has confirmed and exposed the two significant factors, organisational culture and a learning organisation, for leaders to use in their pursuit of enabling the KM agenda in public sector organisations. Further research may look at amounts spent by government organisations on technology as opposed to people (learning, rewarding, incentivising, etc.). This, in turn, requires deeper research into the organisational culture and questions such as 'why' people share, and what the barriers to and enablers of effective sharing are.

Contrary to the question posed by Wilson (2002), knowledge management is not a fad but indeed a discipline that is continuously being embraced by visionary leaders. South African government departments currently face a serious challenge in terms of improving their service delivery commitments to the public. If knowledge management is correctly addressed and implemented, this will certainly enable these departments to meet their national obligation to service excellence. 


\section{Acknowledgements Competing interest}

The authors declare that they have no financial or personal relationship(s) that may have inappropriately influenced them in writing this article.

\section{Authors' contributions}

A.M. (Nelson Mandela Metropolitan University) was the lead researcher and H.J.v.N. (Nelson Mandela Metropolitan University) was the main promoter and responsible for advising on the relevant subject matter. C.M.A. (Nelson Mandela Metropolitan University) was the co-promoter, whose contributions were with regard to the structure and advice on the research process and analysis conducted.

\section{References}

Alavi, M. \& Leidner, D., 1999, 'Knowledge management systems: Issues, challenges, and benefits', Communications of AIS Journal 1, 2-37.

Ardichvili, A., Page, V. \& Wentling, T., 2003, 'Motivation and barriers to participation in virtual knowledge-sharing communities of practice', Journal of Knowledge Management 7(1), 64-77. http://dx.doi.org/10.1108/13673270310463626

Bebensee, T., Helms, R. \& Spruit, M., 2011, 'Exploring web 2.0 applications as a mean of bolstering up knowledge management', The Electronic Journal of Knowledge Management 9(1), 1-9.

Bechina, A. \& Ndlela, N., 2009, 'Success factors in implementing knowledge based systems', Electronic Journal of Knowledge Management 7(2), 211-218.

Campbell, M.J., 2009, 'Identification of organisational cultural factors that impact knowledge sharing', Capstone report presented to the Interdisciplinary Studies Program, Graduate School, University of Oregon.

Cheng, M., Ho, J. \& Lau, P., 2009, 'Knowledge sharing in academic institutions: A study of multimedia university Malaysia', Electronic Journal of Knowledge Management $7(3), 313-324$.

Cloete, F., 2007, 'Knowledge management and trust in government: Lessons from South Africa', paper presented at the 7th Global Forum on Re-inventing Government, Vienna, 26-29 June.

Cong, X. \& Pandya, K., 2003, 'Issues of knowledge management in the public sector', Electronic Journal of Knowledge Management 1(2), 25-33.

Cortes, E., Sa'ez, P. \& Ortega, E., 2007, 'Organizational structure features supporting knowledge management processes', Journal of Knowledge Management 11(4), 45-57. http://dx.doi.org/10.1108/13673270710762701

Cranfield, D.J. \& Taylor, J., 2008, 'Knowledge management and higher education: A UK case study', The Electronic Journal of Knowledge Management 6(2), 85-100.

Cross, R., Borgatti, S.P. \& Parker, A., 2001, 'Beyond answers: Dimensions of the advice network', Social Networks 23(3), 215-235. http://dx.doi.org/10.1016/S03788733(01)00041-7

Dalkir, K., 2005, Knowledge Management in theory and practice, ButterworthHeinemann Publications, Burlington.

Davenport, T.H., DeLong, D.W. \& Beers, M.C., 1998, 'Successful knowledge management projects', Sloan Management Review, 43-57.

Durrant, F., 2001, 'Knowledge management in the context of government', paper presented at a High Level Workshop on E-Government, Information and Communication Technologies in Public Sector Management, Caribbean Ministerial Consultation, Jamaica, 10-14 December.

Economic Intelligence Unit, 2006, A report of the economic, industry and corporate trends for the year 2020, viewed July 2009, from http://graphics.eiu.com/files/ ad_pdfs/eiuForesight2020_WP.pdf
Foos, T., Schum, G. \& Rothenberg, S., 2006, Tacit knowledge transfer and the knowledge disconnect', Journal of Knowledge Management 10(1), 6-18. http:// knowledge disconnect, Journal of Knowledg
dx.doi.org/10.1108/13673270610650067

Gaffoor, S. \& Cloete, F., 2010, 'Knowledge management in local government: The case of Stellenbosch municipality', South African Journal of Information Management 12(1), Art. \#422, 7 pages.

Goh, S.C., 2002, 'Managing effective knowledge transfer: An integrative framework and some practical implications', Journal of Knowledge Management 6(1), 23-30. http://dx.doi.org/10.1108/13673270210417664

Hair, J.F., Anderson, R.E., Tatham, R.L. \& Black, W.C., 1998, Multivariate data analysis, 5 th edn., Prentice Hall, Englewood Cliffs.

Hair, J.F., Black, W.C., Babin, J.B., Anderson, R.E. \& Tatham, R.L., 2006, Multivariate data analysis, 6 th edn., Prentice Hall, Upper Saddle River.

Hsu, I.C., 2006, 'Enhancing employee tendencies to share knowledge - Case studies of nine companies in Taiwan', International Journal of Information Management 26 , 326-338. http://dx.doi.org/10.1016/j.ijinfomgt.2006.03.001

Ibrahim, F. \& Reid, V., 2009, 'What is the value of knowledge management practices?', Electronic Journal of Knowledge Management 7(5), 567-574.

Jakubik, M., 2007, 'Exploring the knowledge landscape: Four emerging views of knowledge', Journal of Knowledge Management 11(4), 6-19. http://dx.doi. org/10.1108/13673270710762675

Kaiser, H.F., 1974, 'An index of factorial simplicity', Psychometrika 39, 31-36. http:// dx.doi.org/10.1007/BF02291575

Kimble, C. \& Hildreth, P., 2005, 'Dualities, distributed communities of practice and knowledge management', Journal of Knowledge Management 9(4), 102-113. http://dx.doi.org/10.1108/13673270510610369

Kippenberger, T., 1998, 'Knowledge management: The current state of play', Management Research 11, 14

Kreitner, R., Kinicki, A. \& Buelens, M., 1999, Organizational behaviour, 1st European edn., McGraw-Hill Publishing, Berkshire.

Mbeki, T., 2012, 'The democratisation of knowledge: The role of knowledge in the betterment of society', address at the knowledge management conference, in Thabo Mbeki Foundation, viewed 29 May 2012, from http:// www.thabombekifoundation.org.za/pages/address-of-the-patron-of-the-tmf, thabo-mbeki,-at-the-university-of-stellenbosch-business-school-knowledgemanagement-speec.aspx

McDermott, R. \& O'Dell, C., 2005, 'Overcoming cultural barriers to sharing knowledge', Journal of Knowledge Management 5(1), 76-85. http://dx.doi. org/10.1108/13673270110384428

Paroutis, S. \& Al Saleh, A., 2009, 'Determinants of knowledge sharing using web 2.0 Technologies', Journal of Knowledge Management 13(4), 52-63. http://dx.doi. org/10.1108/13673270910971824

Riege, A., 2005, 'Three-dozen knowledge-barriers managers must consider', Journal of Knowledge Management 9(3), 18-35. http://dx.doi.org/10.1108/ 13673270510602746

Rogers, G., 2007, 'Clamps on perlemoen poaching ineffectual', Eastern Cape Herald, 16 April, p. 1.

Salavati, A, Shafei, R. \& Shaghayegh, E., 2010, 'A model for adoption of knowledge management in Iranian public organisations', European Journal of Social Sciences 17(1), 109-116.

Scarso, E. \& Bolisani, E., 2011, 'Knowledge-based strategies for knowledge intensive business services: A multiple case-study of computer service companies', Electronic Journal of Knowledge Management 8(1), 151-160.

Schein, E.H., 1996, 'Three cultures of management: The key to organisational learning', The Sloan Management Review 38(1), in harvardmacy.org, viewed October 2010, from http://www.harvardmacy.org/Upload/pdf/Schein\%20artilce.

Tiago, F., Tiago, M.T.B. \& Couto, J.P., 2009, 'Assessing the drivers of virtual knowledge management impact in European firms' performance: An exploratory analysis', Electronic Journal of Knowledge Management 7(2), 277-286.

Wilson, T.D., 2002, 'The nonsense of "knowledge management"', Information Research 8(1)

Yao, L., Kam, T. \& Chan, S., 2007, 'Knowledge sharing in Asian public administration sector: The case of Hong Kong', Journal of Enterprise Information Management 20(1), 51-69.

Yuen, Y., 2007, 'Overview of knowledge management in the public sector', paper delivered at the 7th Global Forum on Reinventing Government: Building Trust in Government, Vienna, Austria, 26-29 June. 